\title{
Genetic and environmental influences on a measure of infant attachment security
}

\author{
Deborah Finkel ${ }^{1}$ and Adam $\mathrm{P}$ Matheny $\mathrm{J}^{2}$ \\ ${ }^{1}$ Indiana University Southeast, New Albany, IN \\ ${ }^{2}$ University of Louisville, KY, USA
}

\begin{abstract}
A twin study of infant attachment security at age 24 months was conducted on archival data for a sample of $99 \mathrm{MZ}$ pairs and $108 \mathrm{DZ}$ pairs from the Louisville Twin Study. MZ concordance for attachment was $62.6 \%$, which was significantly greater than the DZ concordance of $44.4 \%$. Concordances were transformed into polychoric correlations, and LISREL was used to conduct a quantitative genetic analysis of the data. Results indicated that $25 \%$ of the variability in attachment was attributable to genetic factors, and the remaining $75 \%$ was attributable to nonshared environmental effects. No evidence was found for a contribution from shared environmental influences to attachment security. Possible concerns about the validity of twin methodology are addressed and various interpretations of the results are presented. Twin Research (2000) 3 , 242-250.
\end{abstract}

Keywords: attachment security, heritability, non-shared environment, twins

Perhaps the most significant psychosocial event occurring during an infant's first year of life is the development of attachment. Even though attachment can be considered an essential condition for the survival of every member of the human species, ${ }^{1}$ marked individual differences in attachment relationships have been observed. Ainsworth and her colleagues developed the Strange Situation to assess variation in the security of attachment. ${ }^{2,3}$ Several decades of intensive research into the sources of variability in attachment seen in the Strange Situation have produced viewpoints with contrasting emphases: researchers who focus on maternal behavior as the source of individual differences in attachment $^{4-7}$ and researchers who suggest that innate individual differences in infant temperament and emotional reactivity to stress may be a source of individual differences in attachment behavior. ${ }^{8-10}$

Ainsworth ${ }^{4}$ presciently summarized the issue when she asked 'to what extent is the pattern of attachment of a baby attributable to the mother's behavior throughout the first year, and to what extent is it attributable to the built-in differences in potential and temperament'. Researchers have attempted to answer this question by determining the relative contribution of maternal behavior (nurture) and infant characteristics (nature) to attachment security. Results suggest the presence of main effects ${ }^{11-13}$ and

Correspondence: Deborah Finkel, PhD, Division of Social Sciences, Indiana University Southeast, 4201 Grant Line Road, New Albany, IN 47150, USA. Tel: 812941 2668; Fax: 812941 2591; E-mail: dfinkel@us.edu

Received 24 February 2000; revised 14 June 2000; accepted 21 June 2000 interaction effects ${ }^{14,15}$ for both the influence of maternal characteristics and the influence of infant temperament on attachment.

A powerful method for addressing this naturenurture debate may be found by observing the attachment behavior of infant twins. ${ }^{16}$ Application of twin methodology to the question of sources of individual differences for attachment security can be achieved by comparing the similarity of rearedtogether monozygotic (MZ) twins to the similarity of reared-together dizygotic (DZ) twins. If the withinpair similarity for attachment security is higher for $M Z$ pairs than for $D Z$ pairs, then one would have support for the position that attachment develops, in part, from innate infant characteristics. In contrast, equal $M Z$ and $D Z$ similarity for attachment would suggest that there are only environmental effects, thereby supporting the theory that caregiver behavior is the source of attachment security.

Few twin studies of attachment have been conducted. Goldberg, Perotta, and Minde found only seven of 17 twin pairs to be concordant for attachment security, but did not report concordance separately for $M Z$ and $D Z$ pairs. ${ }^{17}$ Vandell, Owen, Wilson, and Henderson linked the development of infant-caregiver attachment to the development of relationships with same-age peers for a sample of $16 \mathrm{MZ}$ and $9 \mathrm{DZ}$ twin pairs. ${ }^{18}$ Unfortunately, Vandell and colleagues did not report twin concordance for attachment classification. Szajnberg, Skrinjaric and Moore reported that three of four pairs of $M Z$ twins were concordant, and two of four DZ pairs were concordant for attachment classification. ${ }^{19}$ Cherro conducted a study of two twin pairs in which 
attachment was assessed using the Strange Situation. $^{20}$ The focus of the study, however, was on parental attitudes about multiple births, and neither attachment data nor zygosity (classification of twin pairs as MZ or DZ) were presented. Gottfried, Seay and Leake included 15 twin pairs in their study using a modified version of the Strange Situation, but did not report twin concordances for attachment. $^{21}$

It is important to note that the original goal of the studies summarized above was not an application of classical twin methodology to attachment per se. Only two studies of attachment for infant twins have applied behavior genetic methodology to the data. Lytton and his colleagues conducted a study with the goal of comparing development in twins and singletons. ${ }^{22,23}$ The sample included $17 \mathrm{MZ}$ pairs and $29 \mathrm{DZ}$ pairs of male twins. Neither of the standard operationalizations of attachment, the Strange Situation or the Attachment Q-set, ${ }^{24}$ were used to measure attachment. Instead, attachment was represented by counting the number of times a child returned to mother during free play and by ratings of the child's reaction to mother's departure. The emphasis of the Strange Situation is on the child's reaction to the mother when she returns after separation. ${ }^{2}$ Behavior genetic model-fitting indicated little or no genetic influence on these unique measures of attachment behavior. In contrast, Ricciuti reported significant genetic influences on individual differences for attachment behavior as measured by the Strange Situation for a sample of $29 \mathrm{MZ}$ twins and $27 \mathrm{DZ}$ twins. ${ }^{25}$

In sum, previous twin studies of attachment are limited by at least one of several factors: small sample sizes, incomplete reporting of twin similarity for attachment, and failure to used widely accepted measures of attachment. In spite of these limitations, many of these studies have been used to support the assumption that there is minimal or no genetic contribution to individual differences for attachment classification. ${ }^{7}$ To make a more conclusive statement, however, a more powerful, accurate, and extensive application of twin methodology is required. The goal of the present investigation was to overcome the limitations of previous studies by applying behavior genetic methods to a valid measure of infant attachment in a large sample of twins. The Louisville Twin Study provided a sample with a sufficient number of twin pairs observed through standardized procedures to conduct a behavior genetic analysis of infant attachment

The Louisville Twin Study (LTS) has obtained longitudinal (infancy to adulthood) assessments for three major areas of developmental study: anthropometric characteristics, cognitive abilities, and temperament. $^{26-29}$ The assessment of temperament included videotaping infant responses to age-appropriate vignettes that include separations from the mother, followed by reunion episodes. ${ }^{30}$ Behavior of the infants during these videotaped vignettes involving separation and reunion can be classified in terms of security of attachment. ${ }^{31}$ The purpose of the present investigation was to view the archival video footage to analyze twin similarity for attachment security at age 24 months for a sample of $99 \mathrm{MZ}$ pairs and $108 \mathrm{DZ}$ pairs.

\section{Method}

\section{Sample}

Twins enrolled in the LTS were recruited from families residing in the metropolitan Louisville, $\mathrm{KY}$, area at the time of the twins' birth. The LTS sample is a randomly selected collection of families who represent the full range of socio-economic status, race, and ethnic diversity within the Louisville metropolitan area. Approximately $80 \%$ of the participants are European-American, $18 \%$ are AfricanAmerican, and the remaining $2 \%$ are of mixed or Asian ancestry. Occupations of heads of hou seholds, converted to Duncan's scores for socio-economic status, $^{32}$ represented the entire distribution of social class, with the average score on the 100-point scale falling between 40 and 50 (score range typical for middle-level clerical workers). Mean gestational age of the LTS sample is 37 weeks, which is just below the population mean of 40 weeks for single-born neonates. Special efforts have been made to retain recruited families in the study, and less than $10 \%$ of the sample withdraws from the Iongitudinal study during the first three years.

Beginning in 1976, infant-caregiver interactions were videotaped. At the time of the present investigation, 218 twin pairs had participated in the LTS procedure at 24 months. Data on the attachment measure were not available for 12 infants from 11 twin pairs as a result of the father's involvement in the procedure (five infants), a research staff member's involvement in the reunion (one infant), incomplete videotape (three infants), or the fact that an infant was asleep during the second reunion (three infants). Even though father-infant attachment is an important area of research, insufficient data dependent on fathers were available for this sample to pursue the issue. As a consequence, attachment data for both members of the pair were available for $207 \mathrm{twin}$ pairs: $99 \mathrm{MZ}$ pairs, 56 samesex DZ pairs, and 52 opposite-sex DZ pairs. Half of the same-sex $D Z$ pairs and $60 \%$ of the $M Z$ pairs were girls.

Zygosity was determined by blood sera analysis made when the twins were 36 months of age or older 
as part of the LTS protocol. Prior to 36 months, zygosity was determined by staff ratings of the twins' similarity of physical appearance. Previous studies have demonstrated that assessments of physical similarity are $90 \%$ to $95 \%$ accurate when compared with serological tests. ${ }^{33}$ Results of blood sera testing were available for $79 \%$ of the sample.

\section{Measures}

Separation and reunion vignettes involving twins, mother, and research staff were videotaped as part of the LTS procedure at age 24 months. ${ }^{34}$ These vignettes provided an approximation of the Strange Situation. Table 1 presents a comparison between the features of both the Strange Situation and the LTS procedure. Similar to the Strange Situation, during the LTS procedure each twin experienced two separations and two reunions with the mother. During the first separation in the LTS procedure, the twins were together with two strangers (research staff), while during the second separation the twins were al one with a stranger. The order in which the twins experienced the second separation was randomized and no order effects on attachment classification were found $\left(\chi^{2}=0.57, \mathrm{df}=2, \mathrm{~ns}\right)$. The LTS procedure differs from the Strange Situation in three distinct ways:

(1) the co-twin is present during the first separation and during reunions,

(2) during separations, twins are participating in a scripted set of play vignettes organized by the strangers, and

(3) the length of the entire LTS procedure is considerably longer than that described for the Strange Situation.

Two steps were taken to provide a close approximation between attachment assessment resulting from the Strange Situation and the LTS attachment assessment. First, results of Gottfried and colleagues suggest that the presence of the co-twins may buffer infants' strong reactions to separation, but after being separated from both mothers and co-twins, infants direct their attachment behavior toward mothers only. ${ }^{21}$ Therefore, only the second reunion for each twin, after being separated from both co-twin and mother, was coded for attachment behavior and formed the primary basis for attachment classification. Second, several attachment researchers have developed modified versions of the Strange Situation for use with older children; the modifications involve lengthening the time period. StevensonHinde and Shouldice used a 45 minute version of the Strange Situation procedure for children at 4.5 years; ${ }^{35}$ Main and Cassidy have developed a method for assessing attachment in 6-year-old children that involves a separation from the parent of 60 minutes. ${ }^{36}$ Therefore, we assumed that a $30 \mathrm{~min}$ ute separation at 24 months was developmentally comparable to a separation of 6 minutes as 12 months.

The validity of the LTS procedure for assessing attachment security was demonstrated for a sample of 32 infants. ${ }^{31}$ Participants were tested using the Strange Situation procedure one month after their regularly scheduled visit to the LTS. Concordance between attachment classifications derived from the two procedures was $78 \% \quad(\kappa=0.52, \mathrm{P}<0.001)$. Furthermore, observed frequencies of $\mathrm{A}, \mathrm{B}$, and $\mathrm{C}$ classifications derived from the LTS procedure did not differ from normative frequencies as reported by Ainsw orth. ${ }^{3}$

\section{Procedure}

Videotapes of the LTS separation and reunion vignettes were viewed by trained observers and scored in terms of attachment behaviors and attachment security. A different observer rated the behavior of each member of a twin pair in order to avoid

Table 1 Comparison of the episodes of the Strange Situation and the Louisville Twin Study procedure

\begin{tabular}{|c|c|c|c|c|}
\hline \multirow[b]{2}{*}{ Episode No. } & \multicolumn{2}{|c|}{ Strange Situation } & \multicolumn{2}{|c|}{ Louisville Twin Study } \\
\hline & Length & Description & Length & Description \\
\hline 1 & $30 \mathrm{~s}$ & Introduction & & \\
\hline 2 & $3 \mathrm{~min}$ & Mother and child & & \\
\hline 3 & $3 \mathrm{~min}$ & Stranger enters & $6 \mathrm{~min}$ & Mother and twins and strangers \\
\hline 4 & $3 \min ^{a}$ & Mother leaves & $18 \mathrm{~min}$ & Mother leaves \\
\hline 5 & $3 \mathrm{~min}$ & Mother returns & $2 \mathrm{~min}$ & Mother returns \\
\hline 6 & $3 \min ^{a}$ & Child alone & & \\
\hline 7 & $3 \min ^{a}$ & Stranger returns & $30 \mathrm{~min}$ & Twin $A$ and stranger $A$ \\
\hline 8 & $3 \mathrm{~min}$ & Mother returns & $1 \mathrm{~min}$ & Mother returns ${ }^{b}$ \\
\hline & & & $30 \mathrm{~min}$ & Twin B and stranger B \\
\hline & & & $1 \mathrm{~min}$ & Mother returns ${ }^{b}$ \\
\hline Total time & $21.5 \mathrm{~min}$ & & $88 \mathrm{~min}$ & \\
\hline
\end{tabular}

${ }^{\mathrm{a} E p i s o d e ~ m a y ~ b e ~ s h o r t e n e d ~ i f ~ c h i l d ~ b e c o m e s ~ v e r y ~ u p s e t ; ~ b ~}{ }^{\mathrm{M}}$ other returns with other twin and other stranger. 
possible observer bias. A total of 11 observers participated in rating videotapes for the 414 individual subjects; how ever five observers were responsible for rating $87.3 \%$ of the infants. Inter-rater agreement was assessed on 20 infants for each observer. Each observer classified $90 \%$ to $100 \%$ of the infants in the same general attachment category $(A, B$, or $C)$ as did the first author. Disagreements were resolved through discussion. As a consequence of training procedures, validity assessments, testing inter-rater reliability, and discussions concerning infants who were difficult to rate, $53.8 \%$ of the tapes were viewed by more than one observer. No evidence of observer effects on attachment classification was found $\left(\chi^{2}=10.81, d f=20, n s\right)$

Statistical method

The basic assumptions underlying the twin design are that:

(1) the shared environmental factors which produce similarities among twin pairs are the same for the $M Z$ and $D Z$ twin pairs,

(2) genetic factors influencing the traits are additive so that the genetic correlation is 1.0 for $M Z$ twins and 0.5 for DZ twins, and

(3) there is no assortative mating for the traits of interest.

When these assumptions are met, the total variance in a trait is typically divided into three components: genetic effects, shared environmental effects, and non-shared environmental effects. Shared environmental factors make family members more si milar to each other, whereas non-shared environmental factors make family members less similar to each other. The correlation between twins, assuming the three components of variance are unrelated, can be expressed as in the following equations.

(1) $\mathrm{MZ}$ correlation $=\mathrm{h}^{2}+\mathrm{c}^{2}$

(2) DZ correlation $=1 / 2 h^{2}+c^{2}$

The symbol $h^{2}$ is the proportion of variance associated with additive genetic factors (ie heritability), and $\mathrm{c}^{2}$ is the proportion of variance associated with shared environmental factors. MZ twins share all their genetic material, thus they have all their genetic variance in common, whereas DZ twins share, on average, one half of their segregating genes so that they have only have of their genetic variance in common. Twins reared in the same household will have in common all the shared environmental variance. A remaining term, $\mathrm{e}^{2}$, represents the proportion of variance associated with non-shared environmental factors and error. Non-shared environmental influences, by definition, do not contrib- ute to twin similarity, however, and so are not included as part of the equations for the correl ations between $M Z$ and $D Z$ twin pairs. By analyzing the observed $M Z$ and $D Z$ correlations, we can estimate the parameters $\mathrm{h}^{2}, \mathrm{c}^{2}$, and $\mathrm{e}^{2}$.

Because attachment classifications represent ordinal data, polychoric twin correlations were calculated and subjected to model fitting procedures using LISREL methods. ${ }^{37}$ The LISREL software package for structural equation modeling provides model-fit statistics (such as $\chi^{2}$ statistic), allowing researchers to examine how well a given behavioral genetic model fits the observed correlations. ${ }^{38}$ LISREL al so provides estimates of $h, c$, and e and the standard errors of these estimates. Polychoric correlations necessitated the use of weighted least squares methods of model fitting. ${ }^{39}$

\section{Results}

To verify that the LTS procedure produced the expected number of $\mathrm{A}, \mathrm{B}$, and $\mathrm{C}$ classifications, observed frequencies were compared to normative frequencies as reported for singleton infants by Ainsworth. ${ }^{3}$ Expected frequencies were $22 \%$ A infants, $65 \%$ B infants, and $13 \% \mathrm{C}$ infants. Observed frequencies were $26.2 \% \mathrm{~A}$ infants, $67.2 \%$ B infants, and $6.6 \% \mathrm{C}$ infants. Observed frequencies did not differ significantly from expected frequencies $\left(\chi^{2}=4.02, \mathrm{df}=2, \mathrm{~ns}\right)$. Although the number of $C$ infants seems less than expected, a recent review of attachment literature suggests that the true normative rate of $C$ infants is $10 \% .{ }^{40}$ No difference in the distribution of attachment categories was found between $M Z$ and $D Z$ twins $\left(\chi^{2}=1.87, \mathrm{df}=4, \mathrm{~ns}\right)$.

Concordance for attachment of $M Z$ and $D Z$ twin pairs is presented in Table2. Using the ABC categories of attachment, the concordance was $62.6 \%$ for $\mathrm{MZ}$ twins $(\kappa=0.20, \mathrm{P}<0.05)$ and $44.4 \%$ for $\mathrm{DZ}$ twins $(\kappa=-0.13, n s)$. Kappa $(\kappa)$ is a coefficient of

Table 2 Twin pair concordance for attachment classifications

\begin{tabular}{lrrrr}
\hline Twin 1 & Twin 2 & & C & Total \\
\hline MZ twin pairs & A & B & & \\
A & 10 & 8 & 1 & 19 \\
B & 19 & 51 & 3 & 73 \\
C & 2 & 4 & 1 & 7 \\
Total & 31 & 63 & 5 & 99 \\
DZ twin pairs & & & & \\
A & 5 & 24 & 2 & 31 \\
B & 20 & 43 & 5 & 68 \\
C & 2 & 7 & 0 & 9 \\
Total & 27 & 74 & 7 & 108 \\
\hline
\end{tabular}


agreement that removes the effects of chance concordance. ${ }^{41}$ Given the large percentage of B infants, the probability of chance concordance is high; the kappa statistic corrects for the differences in expected frequencies for $A, B$, and $C$ infants. Kappa can range from -1.0 to +1.0 . Greater than chance concordance leads to positive values of $\kappa$, less than chance concordance leads to negative values. Thus, MZ twins manifested significantly greater concordance than expected by chance, whereas $D Z$ twins did not. The difference between $M Z$ and $D Z$ twin concordances attained significance $(z=2.93$, $P<0.01)$.

Concordance was also calculated separately for male, female, and opposite sex pairs. Attachment concordance was $60 \%$ for male $M Z$ pairs $(\kappa=0.22$, $P<0.05$ ) and $64.4 \%$ for female $M Z$ pairs $(\kappa=0.18$ ns). Concordance was $39.3 \%$ for male $D Z$ pairs $(\kappa=-0.20, n s), \quad 39.3 \%$ for female $D Z$ pairs ( $\kappa=-0.11, n s$ ), and $50 \%$ for opposite-sex DZ pairs $(\kappa=-0.09$, ns). Gender differences in concordances did not attain statistical significance. Although the concordance rate for opposite-sex DZ pairs was somewhat higher than the concordance rates for both male and female DZ pairs, these differences were not statistically significant. Therefore, quantitative genetic model-fitting procedures were conducted on $M Z$ and DZ twin data combined across gender.

PRELIS- $2^{42}$ was used to translate the twin concordances to polychoric correlations. The resulting correlations were 0.30 for $M Z$ twins $(P<0.01)$ and -0.10 for DZ twins (ns). PRELIS also generated the asymptotic weight matrices necessary for use in weighted least squares estimation of the behavior genetic model. A fully saturated model that included genetic, shared environmental, and nonshared environmental effects was fitted to the data, as well as several nested sub-models. Results of model fitting are presented in Table3. The best fitting model was chosen by minimizing Akaike's Information Criteria (AIC). ${ }^{43}$ Fitting the full model resulted in adequate model fit statistics $\left(\chi^{2}=2.37\right.$, df $\left.=1, \mathrm{AIC}=0.37\right)$. The parameter estimate for genetic effects attained from the full model was 0.25 (confidence interval $[\mathrm{Cl}]=0.00-0.36)$. Parameter estimates for environmental effects were $0.00(\mathrm{Cl}=0.00-0.15)$ for shared

Table 3 Results of biometric model fitting

\begin{tabular}{llllrll}
\hline \multirow{7}{*}{ Model } & \multicolumn{7}{c}{ Change in fit vs model 1} & & \\
& $\chi^{2}$ & $\mathrm{df}$ & $\mathrm{P}$ & $\mathrm{A}$ IC & $\chi^{2}$ change & df change \\
\hline $1 \mathrm{ACE}$ & 2.37 & 1 & 0.50 & 0.37 & & \\
$2 \mathrm{CE}$ & 4.63 & 2 & 0.33 & 0.63 & 2.26 & 1 \\
$3 \mathrm{AE}$ & 2.37 & 2 & 0.67 & -1.63 & 0.00 & 1 \\
$4 \mathrm{E}$ & 8.42 & 3 & 0.13 & 2.42 & $6.05^{\star}$ & 2
\end{tabular}

$\mathrm{A}=$ additive genetic effects; $\mathrm{C}=$ shared environmental effects; $E=$ non-shared environmental effects; AIC=Akaike's Information Criterion; * $\mathrm{P}<0.05$. environment and $0.75(\mathrm{Cl}=0.63-0.98)$ for nonshared environment. Dropping genetic effects from the model (model 2) did not result in a significant change in model fit ( $\chi^{2}$ change $=2.26$, df $=1$, ns). However, when all measures of familiarity are removed from the model (model 4 ), a significant reduction in model fit results $\left(\chi^{2}\right.$ change $=6.05$, $\mathrm{df}=2, \mathrm{P}<0.05$ ). Comparison of $\mathrm{AIC}$ values indicates that the best fitting model is model 3 , which includes only genetic and non-shared environmental effects.

\section{Discussion}

Examination of twin similarity for attachment security measured for a sample of 207 twin pairs indicated significantly greater concordance within $M Z$ twin pairs than within DZ twin pairs. Quantitative genetic model-fitting of the twin polychoric correlations produced a heritability estimate of $25 \%$ for attachment. The remaining $75 \%$ of the variability in attachment was attributed to non-shared environmental factors. The confidence interval around the heritability estimate included zero, and dropping genetic factors from the model failed to result in a significant decrease in model fit. However, dropping both genetic and shared environmental factors from the model did significantly reduce model fit, demonstrating significant family resemblance for attachment security. Akaike's Information Criterion indicated that the best-fitting model included genetic and non-shared environmental factors. Considering the twin concordances and the results of modelfitting, the data suggest modest genetic influences on attachment security. No evidence was found for a significant contribution of shared environmental influences to attachment security. Before we interpret these findings, we must first address possible concerns related to the validity of applying twin methodology to issues of attachment.

One primary concern is the nature of attachment for twins. It is possible that the constructs associated with the diadic relationship between a mother and her infant do not correspond to the triadic relationships that develop among a mother and her twin children. ${ }^{44}$ Two studies of attachment in twin children have addressed this issue. Goldberg and colleagues assessed attachment for 17 twin pairs born at pre-term and 20 singletons born at pre-term to determine whether there was any difficulty in forming attachments with either pre-term infants or two infants at once. ${ }^{17}$ The frequencies of $A, B$, and $C$ attachment classifications for both twins and singletons were similar to the frequencies for full-term infants. They concluded that the twins were no more likely to form insecure attachments than pre-term or 
full-term infants. To examine the possibility that twins develop attachments to their co-twins as well as their parents, Gottfried and colleagues tested 15 twin pairs using a modified version of the Strange Situation. ${ }^{21}$ Infants were accompanied by their co-twin during the first separation and were left al one during the second separation. For the second reunion, both mother and co-twin returned. Results suggested that even though the presence of the co-twin may serve to dampen strong reactions to separation from mother, after separation the infants sought comfort from their mothers and showed no inclination to turn to their returning co-twin for comfort. Twins clearly develop a relationship with their co-twins, but their main attachment figures are their parents.

It is al so important to compare twin concordance for attachment with concordances reported for nontwin siblings. Bub, Johnson, and McCartney used the Q-sort to assess attachment in a sample of 46 sibling pairs. ${ }^{45}$ They reported a non-significant correlation of 0.12 between sibling attachment relationships. Ward, Vaughn and Robb found $57.4 \%$ of 61 sibling pairs concordant for attachment classification using the Strange Situation; ${ }^{46}$ this magnitude is intermediate to the concordances for $M Z$ and $D Z$ twins reported here. The participants in the Ward study were drawn from predominantly urban working class and economically disadvantaged families. Families in the Louisville Twin Study represent a much broader range of the socio-economic spectrum. Possibly as a result of their economically disadvantaged background, there were significantly more insecure-avoidant children in the Ward study than in the present study. It is not surprising, then, that some differences in concordance were found. In spite of the disparity of sample demographics, the sibling concordances reported here and by Ward are fairly similar in magnitude. A recent analysis of sibling concordance for attachment (measured by the Strange Situation) combined data from three research groups, resulting in a sample of 138 sibling pairs. ${ }^{47}$ Sibling concordance for attachment using the $A B C$ classification paradigm failed to attain significance. Only the secure-insecure sibling distributions yielded a significant concordance rate. In sum, DZ concordances reported here are consistent with non-twin sibling concordances reported in the literature.

Another major concern involves possible violation of the basic assumptions of the twin design. One of the principal assumptions is that the shared environmental factors that produce similarities among twin pairs are the same for the $M Z$ and $D Z$ twins. Typically, this assumption is expressed in terms that $M Z$ twins are not treated more similarly than DZ twins. For an investigation involving the possible effects of parental treatment on attachment, concerns about the equal environmental similarity assumption are central. It is possible that greater $M Z$ twin concordance for attachment arises not from shared genes, but from a greater similarity of maternal behavior toward MZ twins. The equal environmental similarity assumption has often been the focus of critiques of behavior genetic investigations; ${ }^{48}$ however, a body of empirical support for the assumption does exist. ${ }^{49}$ For example, researchers have reported that even though $M Z$ twins are, in fact, treated more similarly than DZ twins, greater similarity of treatment was unrelated to twin correlations for characteristics such as cognitive abilities and personality traits. $^{50-52}$

Attachment researchers focus on the behavior of caregivers toward their infants during the first year as the determinant of security of attachment. ${ }^{3}$ DiLalla and Bishop observed mothers interacting with their twin children at ages 7 and 9 months. ${ }^{53}$ They found little evidence that mothers treat $M Z$ twins more similarly than DZ twins during the first year of life. Correlations between gl obal measures of maternal treatment of one co-twin averaged 0.42 for $M Z$ twins and 0.38 for DZ twins. In sum, there is little support for the hypothesis that greater similarity of treatment is influencing the greater $M Z$ twin similarity for attachment security. Given the evidence supporting the validity of the attachment construct in twins and the validity of the basic assumptions of the twin method, it is safe to conclude that the twin design is a legitimate method for investigating the relative influence of maternal behavior and innate infant characteristics on the development of attachment.

Finally, it is necessary to consider possible confounding arising from the archival nature of the data. The videotapes of attachment behavior were recorded over a period of more than 20 years. During that time, parenting styles have changed, ${ }^{54}$ the number of double income families has increased, and more families rely on child daycare. ${ }^{55}$ In sum, cohort effects may make the attachment behavior of infants assessed early in the study significantly different from the attachment behavior of later participants. These potential confounds would be subsumed under shared environmental factors. Examination of the attachment data, however, indicated no significant effects of date of measurement on attachment security. Additionally, twin analysis provided no evidence of significant shared environmental factors. Therefore, the effect of the potential time of measurement confound was inconsequential.

We now turn our attention to the interpretation of the results from the behavior genetic analysis of attachment. The evidence indicates a modest genetic 
influence on attachment security and provides some support for the position that innate infant characteristics play a role in the development of attachment. The data do not suggest that genetic factors determine attachment security; they simply suggest that $25 \%$ of the variability in attachment can be attributed to genetic variance within the population of infants studied. At first glance, a heritability estimate of $25 \%$ seems incompatible with a near zero correlation for DZ twins. However, when the DZ correlation is less than half of its $M Z$ counterpart, as in the present study, non-additive genetic influences are implicated. The genetic factors acting on attachment security may result from the interaction of alleles at the same locus or the interaction of alleles at different loci. The current sample lacked sufficient power to test for genetic non-additivity.

As with many behavior genetic investigations, the present results failed to demonstrate evidence of significant shared environmental influences. It is important to note that shared environment and family environment are not synonymous terms with regard to behavioral genetic analyses. Very simply, shared environmental influences result in similarities among family members, whereas non-shared environmental influences produce differences among family members. Experiences that produce similarities do not necessarily occur within the family context, and experiences within the family context may affect family members differently. ${ }^{56,57}$ Thus, it is inappropriate to interpret an estimate of zero for $c^{2}$ to conclude that maternal behavior has no effect on the development of attachment.

A more reasonable interpretation is that twins are treated differently by their parents and that parental behavior is responded to differently by each infant. DiLalla and Bishop found an average correlation of 0.40 between global measures of maternal treatment of one twin and the co-twin. ${ }^{53}$ Comparing maternal treatment of twins removes the possible confounds of time of measurement and maternal age and experience that exist when comparing singleton siblings. Although it is clearly a strong correlation and highly statistically significant, the correlation for maternal treatment of twins is far from perfect. To some extent, then, mothers treat their infants differently. Even infants who are physically and temperamentally similar are subject to different styles of maternal behavior. In the context of behavior genetic designs, variations in parental treatment would be attributed to a non-shared environmental effect.

Neither is it correct to conclude that the entire $75 \%$ of the variability in attachment attributable to non-shared environmental factors results from differential parental treatment. Non-shared environmental influences al so include events unique to each twin and random error, including measurement error. With regard to error, Colin indicated that good raters will disagree for perhaps $10 \%$ of the ratings of infants, thereby injecting a certain degree of measurement error into the assessment of attachment. ${ }^{40}$ The consequence of measurement error will be an underestimation of heritability. Potential non-shared environmental influences on attachment unrelated to error or differential parental behavior could include differences in prenatal environment, acute and chronic illnesses, and stressful events.

Clearly, this study is only one step toward the identification of the relative contributions of innate infant characteristics and maternal behavior on attachment. One issue that will require resolution is the generalizability of these results to other cultures. Cross-cultural differences in the frequencies of $A, B$, and $C$ classifications have been well documented. ${ }^{58}$ In general, the frequency of $A$ infants tends to be higher in northern European countries, whereas the frequency of $C$ infants is higher in Japan and Israel. Heritability is a population statistic and is thus dependent on the genetic and environmental variation within that population. Consistent cross-cultural differences in parenting behavior may affect the relative contribution of genetic and environmental influences to attachment security. Ideally, twin studies of attachment will be conducted in other cultures to determine whether the finding of $25 \%$ heritability is replicated.

Finally, after having estimated the heritability of infant attachment, behavior geneticists must then begin to identify the specific sources of genetic variance that may underlie that heritability. In other words, the heritability of attachment may reflect genetic influences for related variables, such as specific aspects of temperament or cognitive development. For example, Vaughn and a group of attachment colleagues suggested that attachment and temperament could be conceptualized as overlapping domains, partly because attachment behavior and affect regulation are both measured in a social context. ${ }^{59}$ In effect, the Strange Situation may elicit features of temperament as well as attachment security. When one considers the mounting evidence for significant genetic influences on temperament, ${ }^{60}$ it seems possible that if $\mathrm{MZ}$ twins are more similar than DZ twins for behavior in the Strange Situation, the result accrues from genetic influences on temperament more than (or perhaps instead of) genetic influences on attachment security, per se. Genetic factors may influence attachment indirectly (perhaps through infant temperament), whereas parental behavior may influence attachment security directly. Thus, genetic influences may be a distal determinant of attachment, while the rearing environment may be a proximal determinant. ${ }^{61}$ Also, given the role of representational models in the development of 
attachment, ${ }^{1}$ cognitive development may be an indirect link to the apparent genetic influences on attachment. Behavior genetic methods of analyses exist for addressing the possible overlap among the domains of attachment, temperament, and cognition.

\section{Acknowledgements}

The Louisville Twin Study is supported by grant HD 22637 from the National Institute of Child Heal th and Human Development awarded to Dr Matheny. The authors would like to thank the following for their contributions to this report: Michael Chew, Dana Hardaway, Marie Knear, Melissa McKinley, Paula Mullineaux, Sharon Nuss, Paula Payne, David Ramirez, Aprile Wigginton and Diane Wille.

\section{References}

1 Bowlby J. Attachment and Loss. vol.1. Attachment. Basic Books: New York, 1969.

2 Ainsworth MDS, Wittig BA. Attachment and exploratory behavior of one year olds in a strange situation. In: Foss BM (ed). Determinants of infant behavior. Netheum: London, 1969.

3 Ainsworth MDS, Blehar MC, Waters E, Wall S. Patterns of Attachment: A Psychological Study of the Strange Situation. Erlbaum: Hillsdale, NJ, 1978.

4 Ainsworth MDS. Infant-mother attachment. American Psychologist 1979; 34: 932-937.

5 Blehar M, Liebermann A, Ainsworth MDS. Early face-to-face interaction and its relation to later infant-mother attachment. Child Devel 1977; 48: 182-194.

6 Main M, Tomasini L, Tolan W. Differences among mothers of infants judges to differ in security. Devel Psychol 1979; 15: 472-473.

7 Sroufe LA. Attachment classification from the perspective of infant-caregiver relationships and infant temperament. Child Devel 1985; 56: 1-14

8 Goldsmith HH, Campos J. Toward a theory of infant temperament. In: Emde RN, Harmon RJ (eds). The Development of Attachment and Affiliative Systems. Plenum: New York, 1987.

9 Goldsmith HH, Bradshaw DL, Rieser-Danner LA. Temperament as a potential developmental influence on attachment. In: Lerner N, Lerner RM (eds). Temperament and Social Interaction During Infancy and Childhood. Jossey-Bass: San Francisco, 1986.

10 Kagan J. Psychological Research on the Human Infant: An Evaluative Summary. WT Grant Foundation: New York, 1982.

11 Goldsmith $\mathrm{HH}$, Alansky JA. Maternal and infant temperamental predictors of attachment: A meta-analytic review. J Consult Clin Psychol 1978; 55: 805-816.

12 Izard CE, Haynes OM, Chisholm G, Baak K. Emotional determinants of infant-mother attachment. Child Devel 1991; 62: 906-917.

13 Weber RA, Levitt MJ, Clark MC. Individual variation in attachment security and strange situation behavior: The role of maternal and infant temperament. Child Devel 1986; 57: $56-65$.
14 Mangel sdorf S, Gunnar M, Kestenbaum R, Lang S, Andreas D. Infant proneness-to-distress temperament, maternal personality, and mother-infant attachment: Associations and goodness of fit. Child Devel 1990; 61: 820-831.

15 Susman-Stillman A, Kalkoske M, Egeland B, Waldman I. Infant temperament and maternal sensitivity as predictor of attachment security. Infant Behav Devel 1996; 19: 33-47.

16 Belsky J, Rovine M. Temperament and attachment security in the strange situation: An empirical rapprochement. Child Devel 1987; 58: 787-795.

17 Goldberg S, Perotta M, Minde K. Maternal behavior and attachment in low-birth-weight twins and singletons. Child Devel 1986; 57: 34-46.

18 Vandell DL, Owen MT, Wilson KS, Henderson VK. Social development in infant twins: Peer and mother-child relationships. Child Devel 1988; 59: 168-177.

19 Szajnberg NM, Skrinjaric J, Moore A. Affect attunement, attachment, temperament, and zygosity: A twin study. J Am Acad Child Adolesc Psychiatry 1989; 28: 249-253.

20 Cherro M. Quality of bonding and behavioral differences in twins. Infant Mental Health J 1992; 13: 206-210.

21 Gottfried NW, Seay BM, Leake E. Attachment relationships in infant twins: The effect of co-twin presence during separation from mother. J Genet Psychol 1995; 155: 273-281.

22 Lytton H. Parent-Child Interaction. Plenum: New York, 1980.

23 Lytton H, Conway D, Sauvé R. The impact of twinship on parent-child interaction. J Personality Soc Psychol 1977; 35: 97-107.

24 Waters E, Deane KE. Defining and assessing individual differences in attachment relationships: Q-methodology and the organization of behavior in infancy and early childhood. In: Bretherton I, Waters E (eds). Growing Points of Attachment Theory and Research. Monographs of the Society for Research in Child Development 1985; 50: 41-65.

25 Ricciuti A. Child-Mother Attachment: A Twin Study. Society for Research in Child Development: New Orleans, March, 1993.

26 Falkner F. An appraisal of the potential contribution of Iongitudinal twin studies. In: The Nature and Transmission of the Genetic and Cultural Characteristics of Human Populations. Milbank Memorial Fund: Philadephia, 1957.

27 Vandenberg SG, Stafford RE, Brown AM. The Louisville Twin Study. In: Vandenberg SG (ed). Progress in Human Behavior Genetics. The Johns Hopkins Press, Baltimore, 1968; pp 154-204.

28 Wilson RS. Synchronies in mental development: An epigenetic perspective. Science 1978; 202: 939-948.

29 Matheny AP $\mathrm{t}$. Developmental behavior genetics: Contributions from the Louisville Twin Study. In: Hahn ME, Hewitt JK, Anderson ND, Benno RH (eds). Developmental Behavior Genetics: Neural, Biometrical, and Evolutionary Approaches. Oxford University Press: New York, 1990.

30 Matheny AP $\mathbf{t}$. Play assessment of infant temperament. In: Schaefer C, Gitlin K, Sandgrund A (eds). Play Diagnosis and Assessment. Wiley: New York, 1982.

31 Finkel D, Wille DE, Matheny AP J. Preliminary results from a twin study of infant-caregiver attachment. Behav Genet 1998; 28: 1-8.

32 Duncan OD. Occupations and Social Status. Free Press: New York, 1961.

33 Nichols RC, Bilbro WC. The diagnosis of twin zygosity. Acta Genetica, 1966; 16: 265-275.

34 Matheny AP $\mathfrak{t}$, Wilson RS, Nuss SM. Toddler temperament: Stability across settings and over ages. Child Devel 1984; 55: $1200-1211$.

35 Stevenson-Hinde J, Shouldice A. Maternal interactions and self-reports related to attachment classifications at 4.5 years. Child Devel 1995; 66: 583-596. 
36 Main M, Cassidy J. Categories of response to reunion with the parent at age 6: Predictable from infant attachment classifications and stable over a 1-month period. Devel Psychol 1988; 24: 415-426.

37 Jöreskog KG, Sörbom D. LISREL VII. Scientific Software: Mooresville, IN, 1986.

38 Heath AC, Neale MC, Hewitt KK, Eaves LJ, Fulker DW. Testing structural equation models for twin data using LISREL. Behav Genet 1989; 19: 9-35.

39 Neale MC, Cardon LR. Methodology for Genetic Studies of Twins and Families. Kluwer Academic Publishers: Boston, 1992.

40 Colin VL. Human Attachment. McGraw-Hill: New York, 1996.

41 Cohen J. A coefficient of agreement for nominal scales. Educational and Psychological Measurement 1960; 20: 37-46.

42 J̈reskog KG, Sörbom D. Prelis2 User's Reference Guide. Scientific Software: Chicago, IL, 1993.

43 Akaike H. Factor analysis and aic. Psychometrika 1987; 52: 317-332.

44 Robin M, Kheroua $\mathrm{H}$, Casati I. Effects of early mother-twin relationships from birth to age 3, on twin bonding. Acta Genet Medi Gemellol (Roma) 1992; 41: 143-148.

45 Bub KL, Jhnson MS, McCartney K. A within-family study of mother-child attachment with the Q-sort. Biennial Meeting for the Society for Research in Child Development: Albuquerque, NM, April 1999.

46 Ward MJ, Vaughn BE, Robb MD. Social-emotional adaptation and infant-mother attachment in siblings: Role of the mother in cross-sibling consistency. Child Devel 1988; 59: 643-651.

47 van ljzendorrn M, Moran G, Belsky J, Pederson D, BakermansKranenburg $M$. The similarity of sibling attachments to their mother. In: Moran G, Van Ijzendoorn M. Experiential and Genetic Influences on Attachment: Studies of Siblings and Twins. Symposium of biennial meeting of the Society for Research in Child Development, Albuquerque, NM, April 1999.

48 Baumrind D. The average expectable environment is not good enough: A response to Scarr. Child Devel 1993; 64: 1299-1317.
49 Scarr S. Biological and cultural diversity: The legacy of Darwin for development. Child Devel 1993; 64: 1333-1353.

50 Loehlin JC, Nichols RC. Heredity, Environment and Personality. University of Texas Press: Austin, 1976.

51 Matheny AP $\mathfrak{k}$, Wilson RS, Dolan AB. Relations between twins' similarity in appearance and behavioral similarity: Testing and assumption. Behav Genet 1976; 6: 343-352.

52 Scarr S, Carter-Saltzman L. Twin method: Defense of a critical assumption. Behav Genet 1979; 9: 527-542.

53 DiLalla LF, Bishop EG. Differential maternal treatment of infant twins: Effects of infant behaviors. Behav Genet 1996; 26 : 535-542.

54 Wille D. The 1990s: Gender differences in parenting roles. Sex Roles 1995; 33: 803-817.

55 Hayghe H, Bianchi S. Married mothers' work patterns: Jobfamily compromise. Monthly Labor Review 1994; June, 24-30.

56 Goldsmith $\mathrm{HH}$. Nature-nurture issues in the behavior genetics context: Overcoming barriers to communication. In: Plomin R, McClearn GE (eds). Nature, Nurture and Psychology. American Psychological Corporation: Washington DC, 1993; pp 325-339.

57 Plomin R, Daniels D. Why are children in the same family so different from one another? Behav Brain Sci 1987; 10: 1-16.

58 van Ijzendoorn $\mathrm{MH}$, Kroonenberg PM. Cross-cultural patterns of attachment: A meta-analysis of the Strange Situation. Child Devel 1988; 59: 147-156.

59 Vaughn BE, Stevenson-Hinde J, Waters E, Kotsaftis A, Lefever GB, Shouldice A, Trudel M, Belsky J. Attachment security and temperament in infancy and early childhood: Some conceptual clarifications. Devel Psychol 1992; 28: 463-473.

60 Plomin R, DeFries JC, Fulker DW. Nature and Nurture During Infancy and Early Childhood. Cambridge University Press: Cambridge, 1988.

61 Gottesman II, Goldsmith HH. Developmental psychopathology of antisocial behavior: Inserting genes into its ontogenesis and epigenesis. In: Nelson CE (ed). Threats to Optimal Development: Integrating Biological, Psychological, and Social Risk Factors. Lawrence Erlbaum: Hillsdale, NJ, 1994, pp 69-104. 